\title{
Carbon-Oxygen isotope records of Precambrian metamorphic rocks in the Yeongnam massif area, South Korea
}

\author{
CheOLHONG KiM, AND CHUNGWAN LiM ${ }^{1}$ \\ ${ }^{1}$ Department of Earth Science Education, Kongju National \\ University, Kongju, 32588 Republic of Korea
}

Carbon isotope thermometry between calcite and graphite has been applied to Precambrian granulite facies marbles in the Northeast Yeongnam massif, Gyeongbuk Province Korea. 11 pairs of calcite-graphite samples indicate the peak metamorphic temperature of $752 \square 53^{\circ} \mathrm{C}$ which well matches with the temperature estimated with a petrological study by other researchers. Graphite from this study mainly shows highly lustrous coarse grains and fine crystalline graphite crystals on coarse grains. Thus it well presents the peak metamorphic temperature. Fine graphite crystals on coarse graphite grains are possibly originated from the later stage overgrowth but their high lustrousness may represent prograde metamorphism after formation, which is related to later igneous activity which is related to the Jurassic granite intrusion and near the granite the highest temperature, $835^{\circ} \mathrm{C}$, was obtained. With almost no shift in $\square 13 \mathrm{C}$ and only locally shifted $\square 18 \mathrm{O}$ in the calcite samples of the study area, CO2depleted fluid may have affected the marble at the last stage of metamorphism by the Jurassic granite intrusion. The $\square 13 \mathrm{C}$ and $\square 180$ values of the calcite in the study area show relatively higher values than other Precambrian calcite. It would be interesting to compare the $\mathrm{C}-\mathrm{O}$ isotope values with those from the Cathaysia Craton of the South China Block which is believed to be correlated to Yeongnam massif. 